\title{
Identification of Saharan dust particles in Pleistocene dune sand- paleosol sequences of Fuerteventura (Canary Islands)
}

\author{
György VARGA ${ }^{1}$ and CRIstopher-Bastian ROETTIG ${ }^{2}$
}

\begin{abstract}
Automated static image analysis and newly introduced evaluation techniques were applied in this paper to identify Saharan dust material in the unique sand-paleosol sequence of Fuerteventura (Canary Islands). Measurements of $\sim 50,000$ individual mineral particles per samples provided huge amount of granulometric data on the investigated sedimentary units. In contrast to simple grain size and shape parameters of bulk samples, (1) parametric curve-fitting allowed the separation of different sedimentary populations suggesting the presence of more than one key depositional mechanisms. Additional (2) Raman-spectroscopy of manually targeted individual particles revealed a general relationship among grain size, grayscale intensity and mineralogy. This observation was used to introduce the (3) intensity based assessment technique for identification of large number of quartz particles. The (4) cluster and (5) network analyses showed that only joint analysis of size, shape and grayscale intensity properties provided suitable results, there is no specific granulometric parameter to distinguish Saharan dust due to their irregular shape characteristics. The presented methods allowed the separation of Saharan dust-related quartz grains from local sedimentary deposits, but due to the lack of robust granulometric characterization of coarsest fractions and due to the diverse geochemical properties of North African sources, exact volumetric amount of deposited dust material and sedimentation rates could not be determined from these data.
\end{abstract}

Keywords: Saharan dust; Canary Islands; grain size; grain shape; automated image analysis

\section{Introduction}

Global mineral dust particle emission from arid-semiarid areas can be set into the range between 2 and 3 billion tons per year. Windblown particles are playing important role in several climatic and other environmental processes, while the accumulated eolian dust deposits are valuable climatic archives (Harrison, S.P. et al. 2001; Kohfeld, K. and Tegen, I. 2007; Maher, B.A. et al. 2010; PósFAI, M. and Buseck, P.R. 2010; Shao, Y. et al. 2011). Huge amount of dust is deposited far from the source area, contributing to local sedimentary units as exotic mineral material and has an influence on parent material for soils. Examples for atmospheric dust addition with significantly different geochemical fingerprint were reported from several places, e.g. quartz-rich dust addition to basaltic environments: Hawaii (JACKsON, M.L. et al. 1971); Cheju (Lim, J. et al. 2005); San Clemente Island (Muns, D.R. et al. 2007b); Canary Islands (Coude-Gaussen, G. et al. 1987); clayrich dust delivery to Caribbean soils (ProsPERO, J.M. and LAMB, P.J. 2003) and Florida (Muns, D.R. et al. 2007a) and dust contribution to the formation of red soils in the Medi-

\footnotetext{
${ }^{1}$ Geographical Institute, Research Centre for Astronomy and Earth Sciences, Hungarian Academy of Sciences, Budaörsi út 45, H-1112, Budapest, Hungary. Corresponding author's e-mail: varga.gyorgy@csfk.mta.hu ${ }^{2}$ Institute of Geography, Dresden University of Technology, Helmholtzstraße 10. 01069 Dresden, Germany. E-mail: christopher-bastian.roettig@tu-dresden.de
} 
terranean (YAALON, D.H. and GANOR, E. 1973; MacLeod, D.A. 1980; YAALON, D.H. 1997) or in Australia (MeE, A.C. et al. 2004).

North African regions are responsible for 50-70 per cent of the global dust budget and are regarded as the most intense and dominant sources of atmospheric eolian dust (Tegen, I. et al. 1996; Mahowald, N.M. et al. 1999, 2006; Ginoux, P.M. et al. 2001; Miller, R.L. et al. 2004). This dust is transported into the direction of Europe, Middle East and the Atlantic Ocean (Israelevich, P.L. et al. 2002; BARKAn, J. et al. 2005; ENGelstaedter, S. et al. 2006; Stuut, J.-B.W. et al. 2009). The largest amount is transported westward by high altitude Saharan Air Layer towards the Canary Islands, Caribbean and North America, and by the so-called 'Harmattan' winds of the northeasterly trade winds to South Atlantic and South America (Prospero, J.M. et al. 1970; Swap, R. et al. 1992; Prospero, J.M. 1996).

Fuerteventura is the second largest member of the archipelago of the Canary Islands located closest to the African continent, 100 kilometres west of Morocco. The basaltic Eastern Canary Islands are influenced by Saharan dust events, locally called 'Calima' (Figure 1). The silt, clay and very fine-sand sized mineral particles are deposited on the widespread, shelf-originated carbon- ate eolianites of the island. Cyclic nature of Quaternary climates, changing amount of transported mineral dust, sea-level variations and related sand availability created a unique carbonate sand dune-paleosol sequence on the basaltic island, making it an excellent natural laboratory to study the complex Quaternary eolian dynamics (Roetrig, C-B. et al. 2017). The sedimentary deposits are excellent archives of past environmental changes and landscape evolution history. It is especially true for relatively isolated areas, where to some extent limited transport and depositional mechanisms have played a role in the formation of sedimentary deposits.

The present study aims to (1) provide information on granulometric character of various windblown deposits of Fuerteventura; (2) present a set of new methods to identify Saharan dust material in the carbonate eolianite-paleosol sequences of the island. Both of these proposed aims will be discussed by using the results of automated static image analysis technique. Determination of granulometric parameters is standing in the focal point of sedimentary studies and it is of growing interest in the Earth sciences. Accurate grain size and shape data of sedimentary deposits provide valuable information on entrainment, transport and accumu-
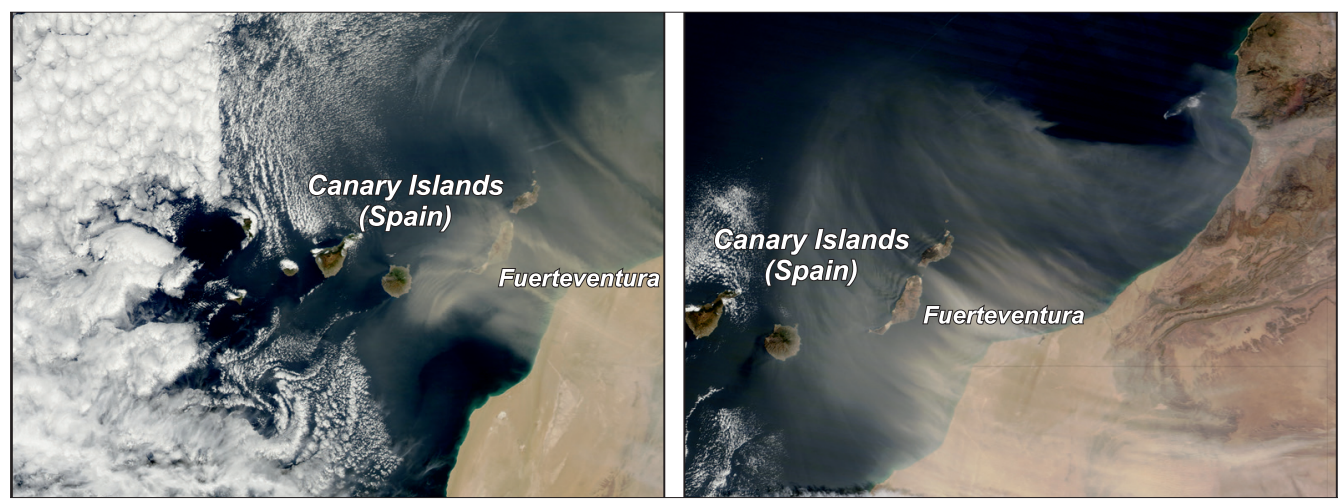

Fig.1. Location of Fuerteventura (Canary Islands) and satellite images of Saharan dust events on $4^{\text {th }}$ February 2013 (NASA Aqua MODIS) (on the left), and on $8^{\text {th }}$ March 2012 (NASA Terra MODIS) (on the right). Source: https://worldview.earthdata.nasa.gov/ 
lation mechanisms of sedimentary particles, and makes us able to gain insights into soil erodibility (CENTERI, Cs. et al. 2015).

\section{Investigation area}

Geological setting of Fuerteventura can be characterized by the products of Neogene and Quaternary alkali basaltic volcanism, unconsolidated carbonate eolianites delivered from exposed shelf areas of the island and admixtured Saharan dust material. Paleo-dune fields and sand sheets of coarse grained biogenetic sandy shelf material with intercalated silty paleosols provide insight into the complex eolian dynamics of the Quaternary. Main phases of sand accumulation are dependent on sand availability and geomorphic stability determined by humiditydriven soil formation. However, as it was reported by CRIAdo, C. et al. (2012), not all reddish layers are in-situ soils, but rather they are formed by higher admixture of siltsized Saharan dust material with quartz and calcite with some additional feldspar, illite, kaolinite and hematite during periods of reduced sand supply (Roettig, C-B. et al. in press). Nowadays, sand availability has also been a key-issue at the island as the demand for sand has grown tremendously by road and building constructions

The identification of past Saharan dust particles and the assessment of their admixture into terrestrial archives play a key role in (1) the understanding of past climate-driven atmospheric circulations; (2) recognition of periods with stable geomorphic evolution and soil formation. Recent observations and measurements allow us to get an overview on dust transportation, deposition and general characteristics of Saharan dust particles. Three different synoptic meteorological situations have to be taken into account regarding the dust availability on Fuerteventura: (1) low altitude easterly winds dominant all year long with winter-spring maximum; (2) summertime dust-bearing Saharan Air Layer as a results of northward migration of the inter- tropical convergence zone (although the main dust transport route is between $\mathrm{N} 15^{\circ}-21^{\circ}$, a southerly component of flow occur in the lee of the easterly wave); (3) low-level continental trade winds. Modern annual Saharan dust deposition rate is around 20 to $80 \mathrm{~g} / \mathrm{m}^{2} /$ year in the region, the reported grain sizes are primarily in the medium and coarse silt fractions (Menéndez, I. et al. 2007). The amount of deposited dust in the past could even be significantly higher (TsOAR, H. and PyE, K. 1987).

\section{Methods}

\section{Granulometric characterization of eolian deposits}

Samples were taken from 24 silty units considered as paleo-surfaces of stable geomorphic periods with reduced sand movements and relatively enhanced Saharan dust influence, additional dune sand and sand sheet samples were also investigated as references for intense sand transportation intervals. Detailed description of the units and stratigraphic analysis of selected sites can be found in the works of FAust, D. et al. (2015) and Roettig, C-B. et al. (2017, in press). Airdried and $2 \mathrm{~mm}$ sieved samples were measured by Malvern Morphologi G3-ID instrument in the Laboratory for Sediment and Soil Analysis (Geographical Institute, Research Centre for Astronomy and Earth Sciences, Hungarian Academy of Sciences).

The applied automated static image analysis technique is a new, innovative mode of grain size and shape analyses completed with chemical identity assessments of Raman spectrometry. In contrast to widely used laser diffraction measurements, image analysis provides direct observational data of particle size, and due to the automatic measurement technique large number of particles are characterized allowing us a more robust and objective granulometric description of particles compared to manual microscopic approaches (Figure 2).

$7 \mathrm{~mm}^{3}$ of mineral particles per samples were dispersed by 4 bar compressed air onto a glass slide with $60 \mathrm{~s}$ settling time. The used 


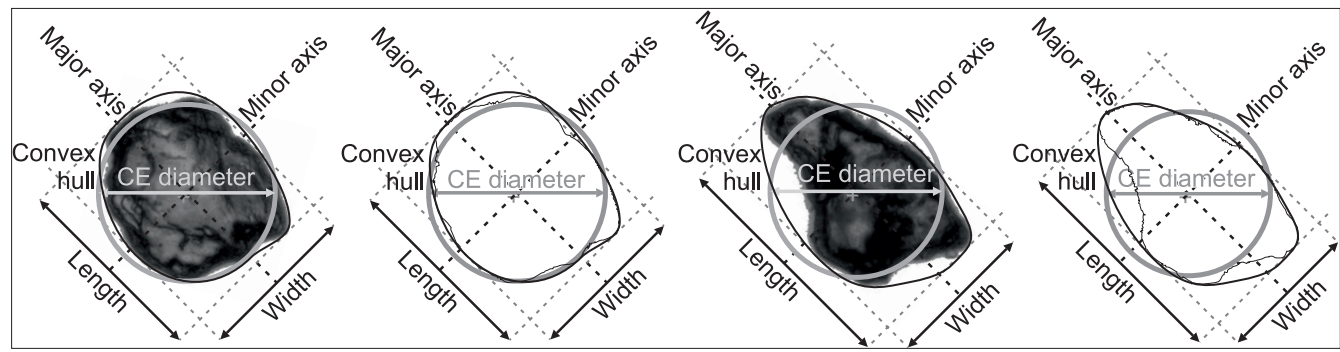

Fig. 2. Key grain size and shape parameters of mineral particles (modified after VARGA, Gy. et al. 2018). - Aspect Ratio $=$ Width/Length; CE Diameter $=$ diameter of a circle with the same area as the projected 2D particle image; Circularity $=\left(2 \times \Pi^{0.5} \times\right.$ Area $\left.^{0.5}\right) /$ Perimeter; Convexity $=$ Perimeter $_{\text {Convex hull }} /$ Perimeter; Elongation $=1-$ Width $/$ Length, the same as $1-$ Aspect Ratio; SE Volume = volume of a sphere with the same CE Diameter as the projected 2D particle image; Solidity $=\mathrm{Area}_{\text {Convex hull }} /$ Area

20 x objective lens provide a $960 \times$ magnification, suitable for detailed characterization of particles in the size range between fine silt and fine sand fractions. Two-dimensional imaging was completed with the usage of additional vertical focal planes, two additional layers were applied above and two other ones below the focus, equivalent to a total of $27.5 \mu \mathrm{m}$.

The captured high-resolution grayscale images of $\sim 50,000$ individual mineral particles were automatically analysed by the device software to get a raw granulometric data-matrix. Each row of the table represents one sedimentary particle (with its own identity number), while the columns are various size and shape parameters, completed with light transmissivity data and Raman correlation scores.

Circle-equivalent (CE) diameter is the key size descriptor, calculated as the diameter of a circle with the same area as the projected twodimensional image of a given mineral grain. Beside several other simple size properties (e.g. length, width, perimeter, sphere-equivalent volume), various shape parameters are derived from these sizes. Aspect ratio is the ratio of width and length, circularity describes the proportional relationship between circumference of a circle equal to the projected area of the particle and perimeter. Convexity (and solidity) parameters are measures of edge roughness by using the ratio of particle and convex hull perimeter (and area). Circularity and convexity values are also suitable to filter out stacked particles and aggregated particles, in this study particles with lower than 0.65 circularity and convexity values were excluded from further calculations.

Intensity mean and standard deviation parameters are determined from the grayscale images as a results of light transmissivity of particles. These values are dependent on mineralogy, particle thickness, chemical homogeneity and surface roughness (for detailed description of the method, see: VARGA, Gr. et al. 2018). Intensity values together with chemical identity analyses of the build-in Raman spectrometer provide useful additional information for separation of granulometrically similar particles.

\section{Identification of Saharan dust material}

Based on the fact that the Saharan dust deposited at Fuerteventura is mainly (1) siltsized and (2) contains a lot of quartz particles (regarded as exotic in the basaltic and carbonate-rich environment of the island), these two deterministic factors were evaluated separately to identify North African dust particles. Three different assessment methods were applied to determine the amount of Saharan dust material of the samples.

An indirect approach was applied to theoretically discriminate the silt-sized sedimen- 
tary subpopulations which were mathematically separated. The polymodal grain size distribution curves were partitioned into several unimodal Weibull-distributions by applying parametric curve-fitting technique (Sun, D. et al. 2002, 2004; VARGA, Gy. et al. in press). According to the applied parametric curve fitting technique the polymodal particle size curves can be interpreted as sum of several, in this case three overlapping Weibull-functions which represent three sediment populations:
Cluster and networks analysis techniques were also applied to differentiate various mineral particle populations based on their general normalized shape (aspect ratio, circularity, convexity, solidity) and grayscale intensity (mean, standard deviation) values. Hierarchical cluster trees were created by using the Euclidean distance pairs of the selected parameters of separated quartz and carbonate size fractions (fine, medium, coarse silt and sand).

$$
W_{1}+W_{2}+W_{3}=c_{1} \cdot\left(\frac{\alpha_{1}}{\beta_{1}^{\alpha_{1}}}\right) \cdot x^{\alpha_{1}-1} \cdot e^{-\left(\frac{x}{\beta_{1}}\right)^{\alpha_{1}}}+c_{2} \cdot\left(\frac{\alpha_{2}}{\beta_{2}^{\alpha_{2}}}\right) \cdot x^{\alpha_{2}-1} \cdot e^{-\left(\frac{x}{\beta_{2}}\right)^{\alpha_{2}}}+c_{3} \cdot\left(\frac{\alpha_{3}}{\beta_{3}^{\alpha_{3}}}\right) \cdot x^{\alpha_{3}-1} \cdot e^{-\left(\frac{x}{\beta_{3}}\right)^{\alpha_{3}}},
$$

where, shape $\left(\alpha_{1-3}\right)$, location $\left(\beta_{1-3}\right)$ and weighting $\left(c_{1-3}\right)$ parameters of the three Weibullfunctions were modified by an iterative numerical method as a least-square problem to assess the appropriate goodness of fit of measured data and calculated size distributions of constructed subpopulations (VARGA, Gr. et al. 2012, in press). According to published data on recent dust events from the area (Criado, C. and Dorta, P. 2003; von Suchodoletz, H. et al. 2009; Menéndez, I. et al. 2013) and measurements of other fartravelled North African dust material (VARGA, Gy. et al. 2016), the subpopulation with smallest particles are regarded as the product of long-ranged dust transport.

Raman-spectroscopy (at $785 \mathrm{~nm}$ wavelength with $3 \mu \mathrm{m}$ spot) was also applied to directly identify the quartz grains as an indicator of Saharan dust contribution. The acquired spectra of targeted particles were compared to Raman spectral reference libraries using KnowitAll@ software from Bio-Rad to identify the minerals present.

The third applied technique was based on the grayscale intensity mean values of particles, the relatively high values were used as a proxy for quartz grains as it was found that there is a strong correlation between light transmissivity and chemical identity (especially in this special case of an environment characterized with the overwhelming majority of carbonate and quartz particles).
For network analysis $192 \times 192$ ([24 samples $\times 2$ minerals $\times 4$ size fractions] $\times$ [24 $\times 2 \times$ 4]) matrix was compiled, where coefficient of determination was calculated for each pair of records based on the normalized shape and grayscale intensity parameters. This matrix was transformed into an adjacency matrix with values of 0 , if $r^{2}<0.99$ and 1 , if $r^{2} \geq 0.99$, in this way all of the similar mineral grains were coupled and the whole database can be handled as a network or a finite graph, where the similar records (nodes) are connected (edges) to each other. The Gephi network visualization software was used to analyse the compiled network by applying the ForceAtlas2 continuous graph layout algorithm (JАСомY, M. et al. 2014).

\section{Results}

General granulometric character of sedimentary samples from Fuerteventura

Grain size distribution curves of samples from the paleo surface units were polymodal, mostly with two-three distinct peaks in coarse silt, fine sand and medium sand fractions. Samples taken additionally from sand members of the sedimentary sequence showed a pure unimodal distribution almost entirely in the sand fractions. It is also worth noting, that even these medium and coarse 
sand dominated samples contained small amount $(<0.5$ vol. $\%)$ of silt-sized particles.

General granulometric characteristics by size fractions are presented in Table 1. and Figure 3. The dominance of sand-sized fraction is clearly visible on circle-equivalent diameter, length and width box-plots; this fraction determines also the bulk grain size values. Shape parameters of samples showed a more diverse picture. Mean aspect ratio values were between 0.75 and 0.80 for all fractions, but higher standard deviation scores could be observed in case of sand-sized particles. Circularity and convexity parameters of silt grains were relatively high, especially compared to sand particles, which had a more irregular shape character. Particles with highest solidity values were from the medium and coarse silt-sized fractions, solidity parameters of fine silt- and sand-sized grains were lower, but in case of clay particles it could be the result of the small number of pixels on the acquired images of individual clay-sized grains.

\section{Parametric curve-fitting: the mathematical- statistical approach}

All of the measured volume-based grain size distribution curves of the measured samples showed a polymodal character. Beside the sand-sized modes, a clear medium and coarse silt-sized peak is present on the diagrams. By using three three-parameter Weibull-distribution functions, proper goodness-of-fit values were reached among the constructed and measured distributions $\left(\mathrm{r}^{2}\right.$ values were $0.98 \pm 0.2)$ during the parametric curve-fitting (Figure 4).

Samples could be represented by diverse grain size distributions; the amount of the coarsest fraction was especially various. During the measurements an average of $\sim 50,000$ individual mineral particles were scanned, so even a few sand-sized grains could have a significant effect on volumebased grain size distributions. As the result of polydisperse grain size of samples (parti- cle sizes covering several orders of magnitude: submicron to some few hundred microns) to get a more robust representation several millions of scanned mineral particles would be necessary (VARGA, Gr. et al. 2018).

Mean modal value of circle-equivalent diameter was $62.3 \mu \mathrm{m}( \pm 12.1 \mu \mathrm{m}$ standard deviation), while the average median was calculated as $49.2 \mu \mathrm{m}( \pm 9.5 \mu \mathrm{m}$ standard deviation) for the 24 samples.

\section{Direct differentiation of quartz grains via Raman-spectroscopy}

The applied measurement system of Malvern Morphology G3-ID enables the chemical characterization of dispersed mineral particles with the use of integrated Raman probe. Due to the relatively low number of interpretable spectra, special focus was given to the medium silt to fine sand-sized components of the samples studied. Only few hundreds of 30-120 $\mu \mathrm{m}$ quartz (Raman shift $\sim 464 \mathrm{~cm}^{-1}$ and carbonate (Raman shift $\sim 1,086 \mathrm{~cm}^{-1}$ ) grains were identified, and this low number of particles did not allow a mathematically robust, quantitative determination of quartz content.

However, some general, broad conclusions could be drawn based on the whole mass of measured samples. Two distinct clusters of quartz and carbonate particles were visible on the circle-equivalent diameter and mean grayscale intensity scatterplots. As mean intensity scores are primarily dependent on particle thickness and mineralogy, with the assumptions of high proportion of isotropic particles, lower circle-equivalent diameter results a higher mean grayscale intensity values (Figure 5). This relationship is clearly visible in case of carbonate particles, but quartz grains are lighter in colour, these can be characterized by higher grayscale intensity values.

General grain size properties of the identified quartz and carbonate particles are also presented. As the selection of mineral grains for manually targeted chemical identity analysis cannot be regarded as representative due to the relatively high number of not 


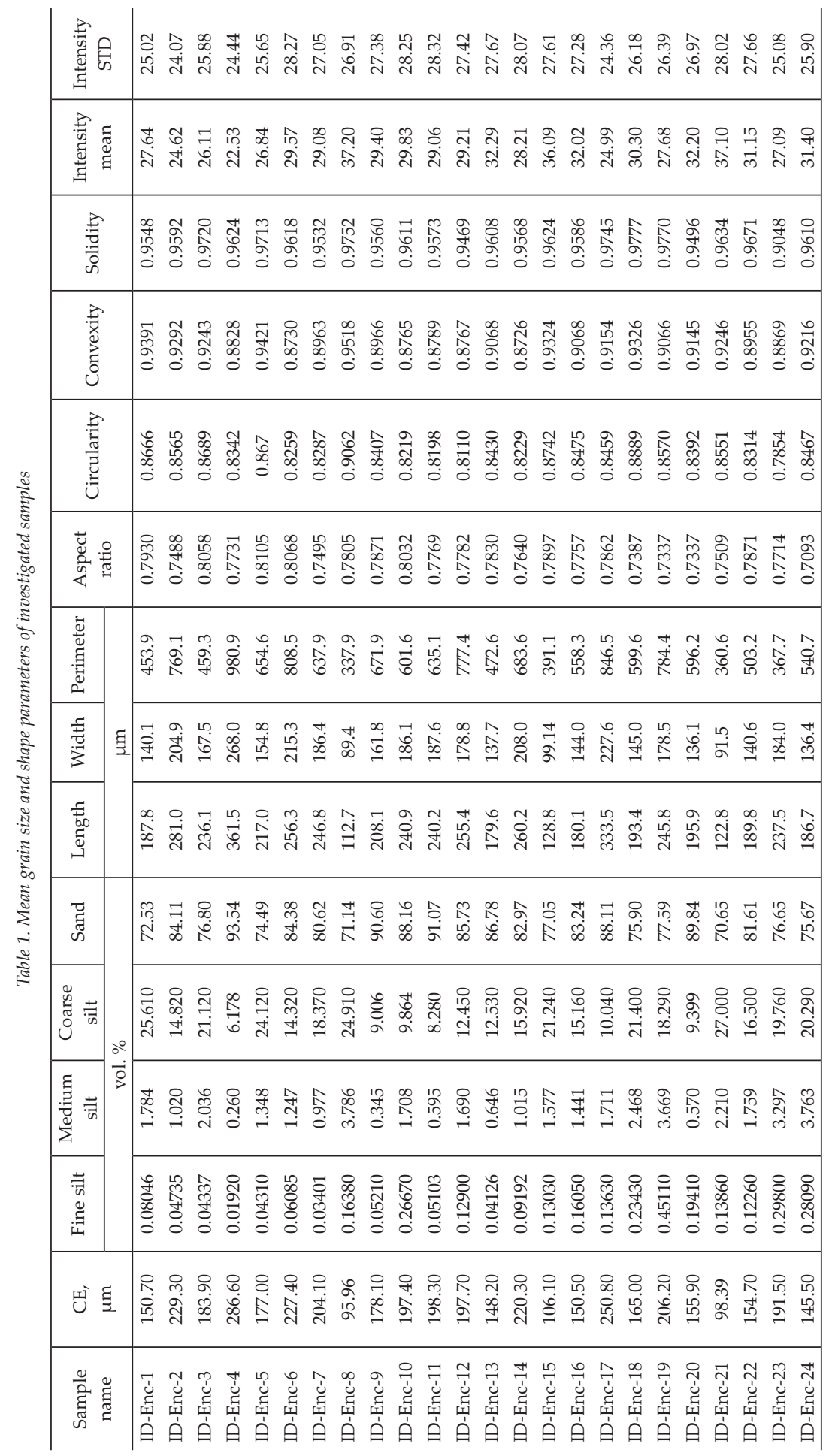




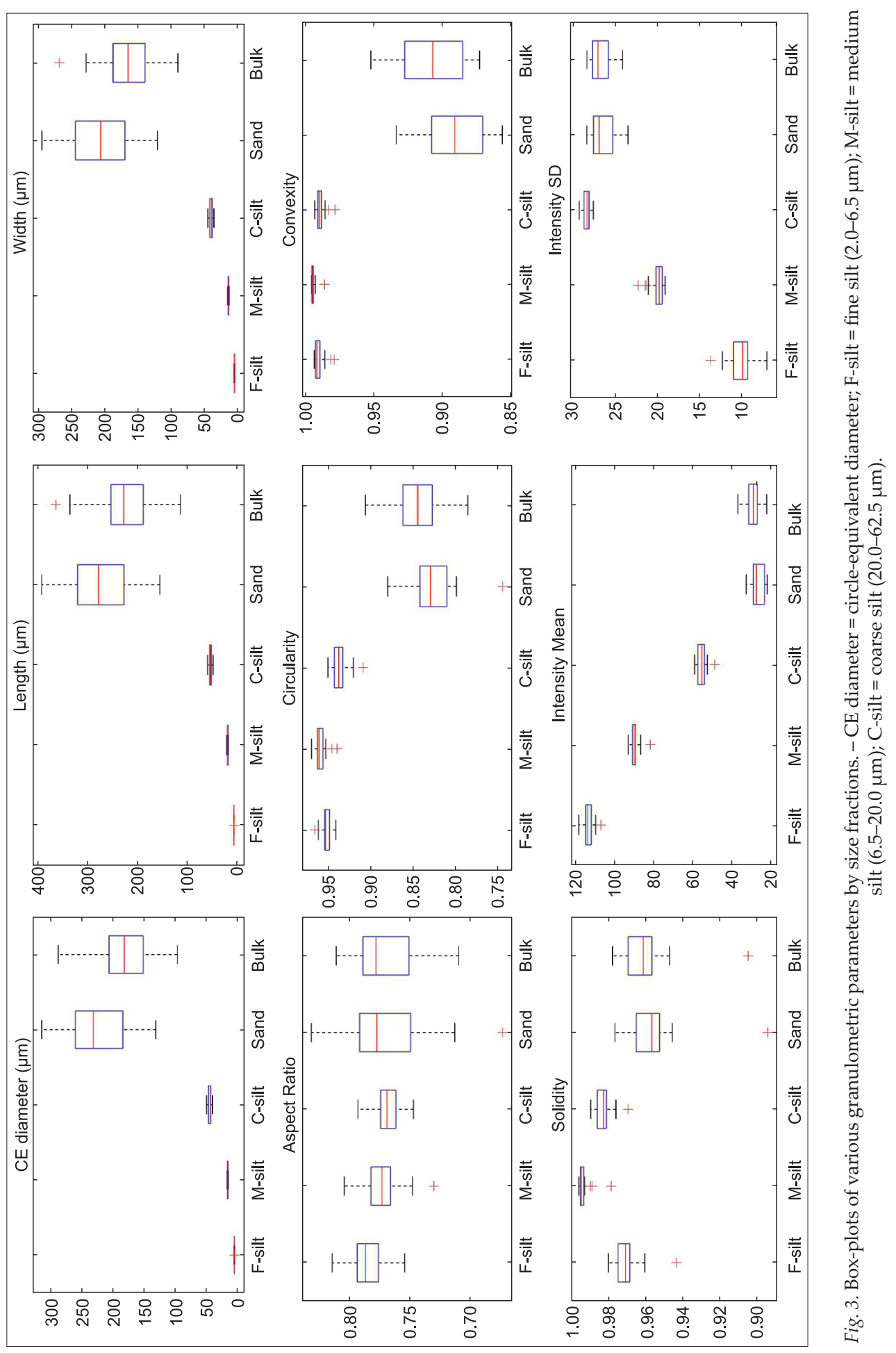



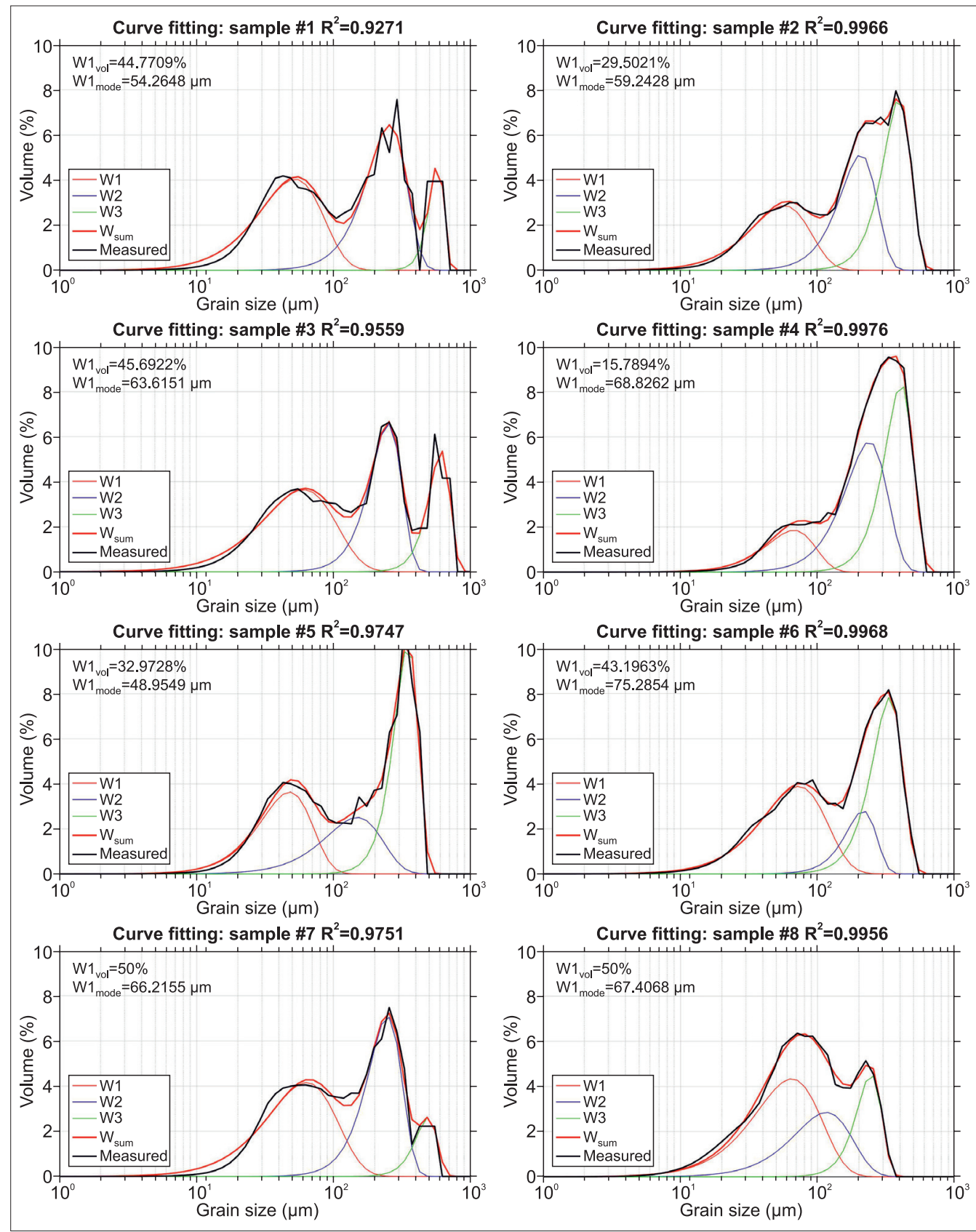

Fig. 4. Results of parametric curve-fitting of the measured grain size distributions 

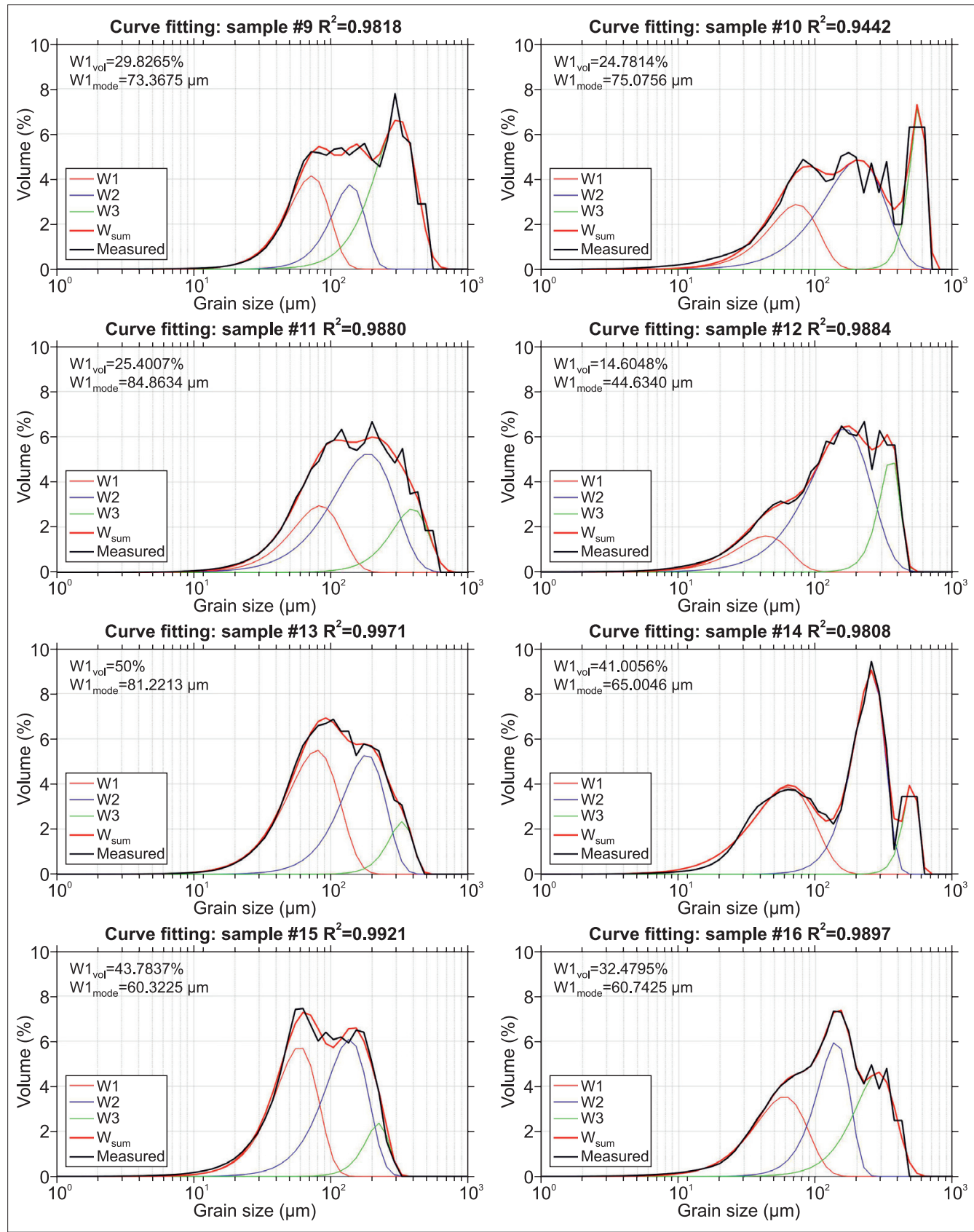

Fig. 4. Continued 

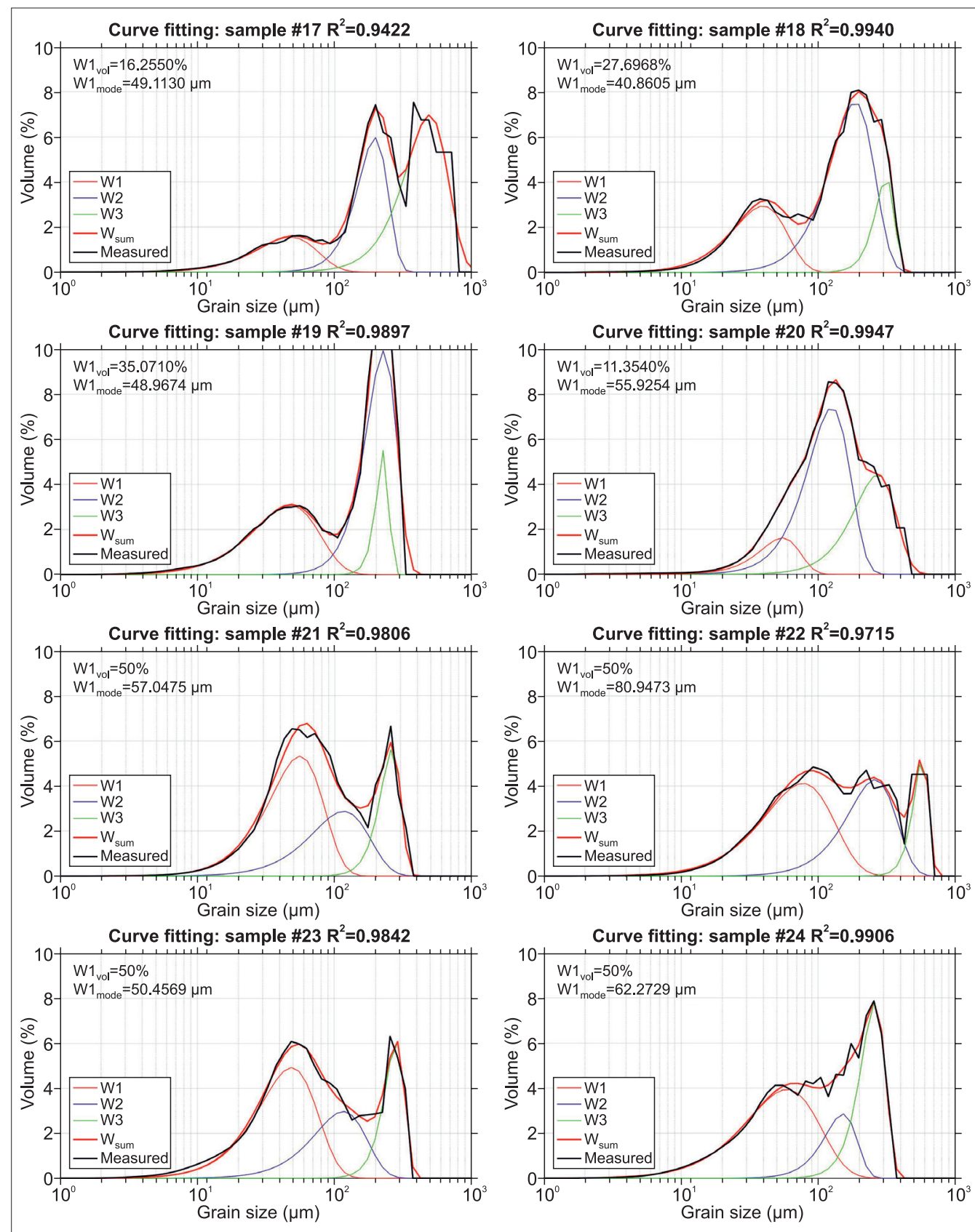

Fig. 4. Continued 


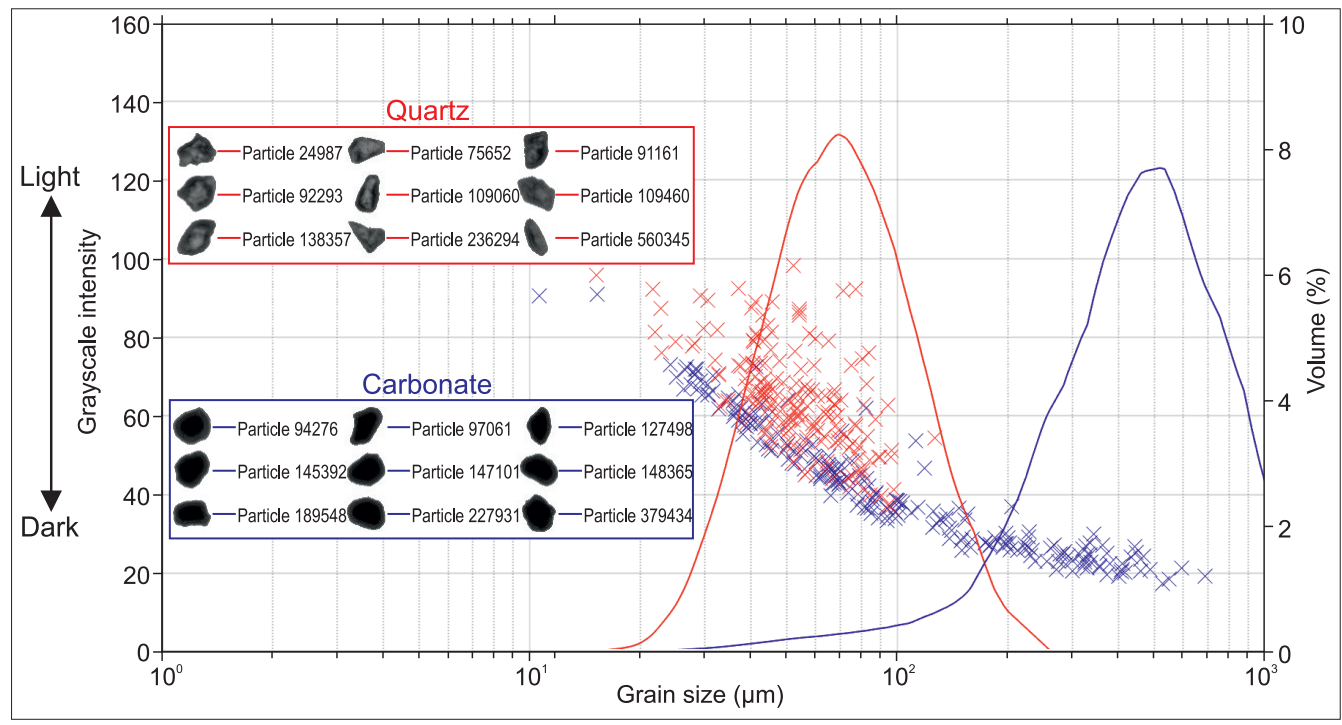

Fig. 5. Relationship among grain size, grayscale intensity and mineral composition of particles on a grains size vs. intensity scatter plot of quartz and carbonate particles.

interpretable acquired Raman spectra, it is assumed that the grain size distributions are somewhat higher (quartz mode: $\sim 70 \mu \mathrm{m}$, median: $68.5 \mu \mathrm{m}$; carbonate mode: $\sim 520 \mu \mathrm{m}$, median: $\sim 460 \mu \mathrm{m}$ ) than the real particle sizes.

Grayscale intensity-based indirect assessment of quartz particles

The automatically recorded dimensionless grayscale intensity values served as proxies of optical properties of mineral grains. As it was above shown above, two distinct groups of particles could be separated on the grain size - grayscale intensity scatter plots, and the acquired Raman spectra confirmed our hypothesis that in a given size-class the grayscale intensities of quartz particles were higher, meaning brighter (lighter in colour) grains.

By using this observation, we applied specific grayscale intensity threshold values $(+5 \%$; $+1 \sigma$ [standard deviation] above size-class mean intensities) for every size-classes to identify possible quartz particles (Figure 6 ). While $+1 \sigma$ thresholds provided too many outliers (probably caused by the low number of scanned particles), the +5 per cent filtering resulted an average of modal value around $65.1 \mu \mathrm{m}( \pm 12.7$ $\mu \mathrm{m}$ standard deviation) and mean median of the 24 samples was $48.3 \mu \mathrm{m}( \pm 6.7 \mu \mathrm{m}$ standard deviation). These values were very similar to the results of fine-grained populations of parametric curve-fittings (W1s), but grain size mode and median of the directly identified quartz particles were slightly higher.

\section{Discussion}

Irregular shape character of the quartz particles

The obtained results of the applied various methods demonstrated that quartz and carbonate particles could be distinguished by simultaneous analysis of size, shape and grayscale intensity values of the investigated samples. Cluster analysis of shape parameters of medium and coarse silt-sized quartz and carbonate particles showed that the two 


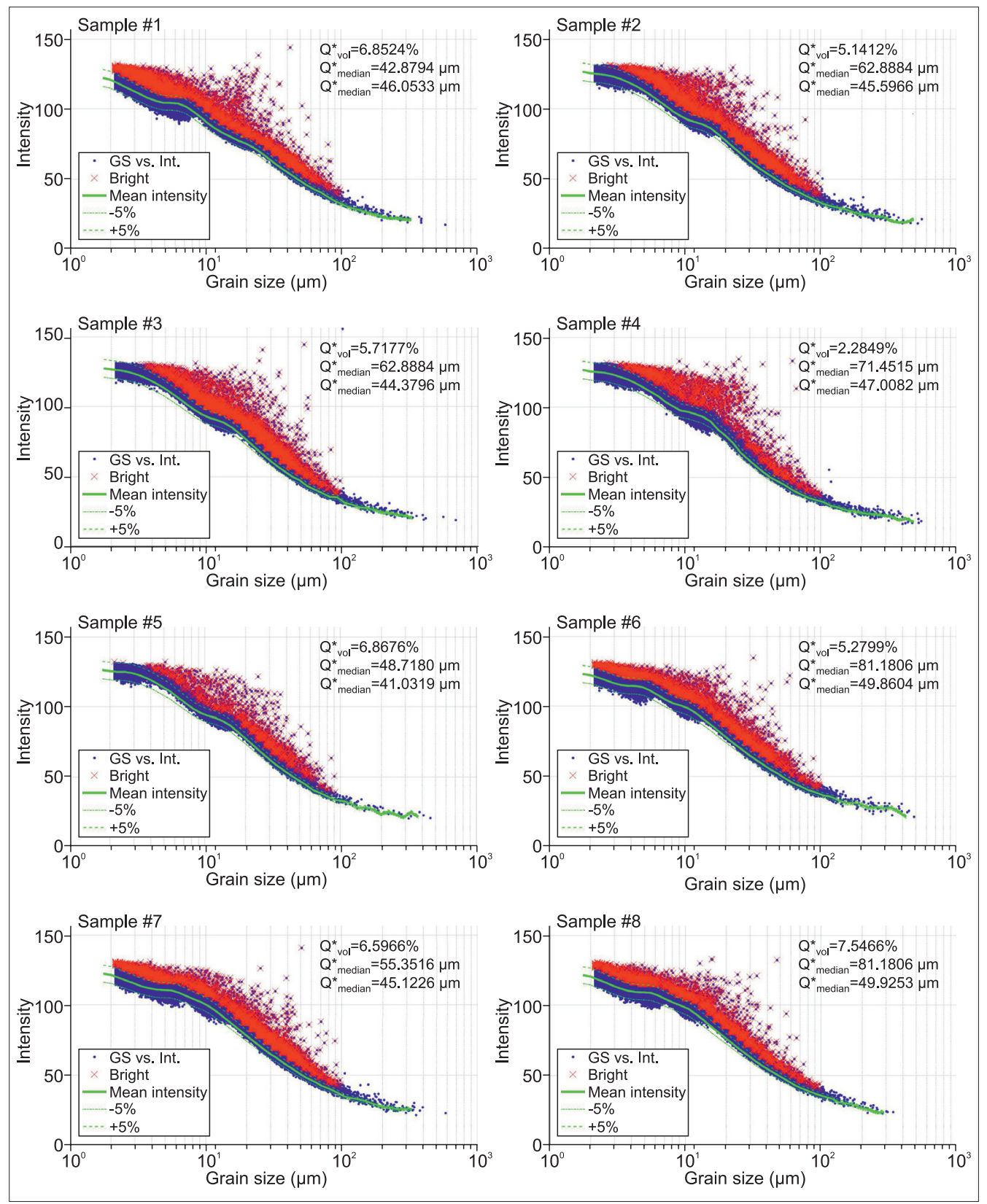

Fig. 6. Intensity-based assessment of quartz particles based on filtering of +5 per cent above size-class means of intensity

populations were well separated from each other, suggesting main shape properties of the two clusters could be determined to serve as granulometric fingerprint to identify external quartz particles in the investigated depositional environment (Figure 7). However, detailed 

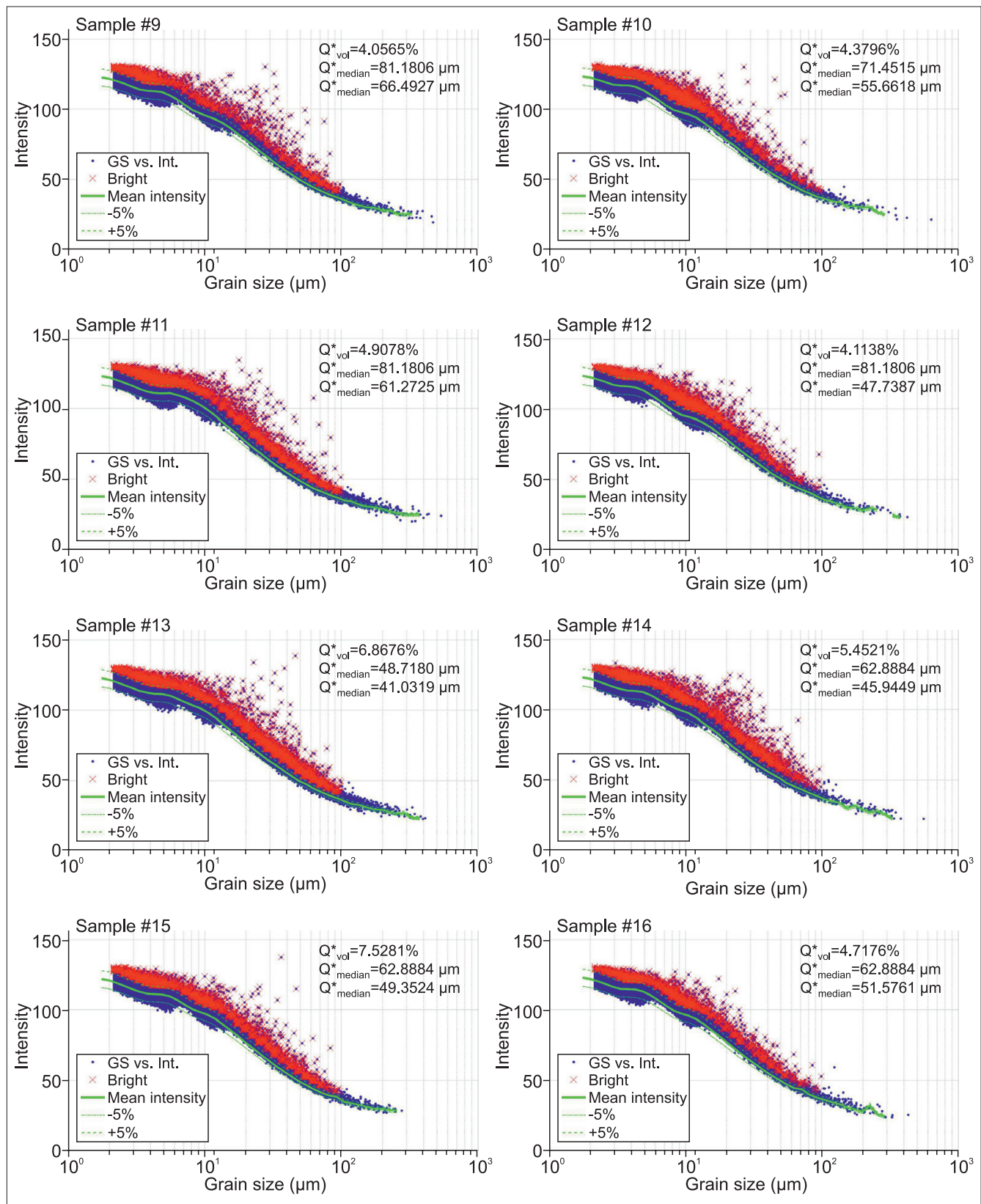

Fig. 6. Continued

analysis of different parameters indicated that the homogeneous-inhomogeneous shape characters of carbonate and quartz particles were the main drivers of clustering. All shape parameters in all size fractions were falling into a wider range in case of quartz particles, 


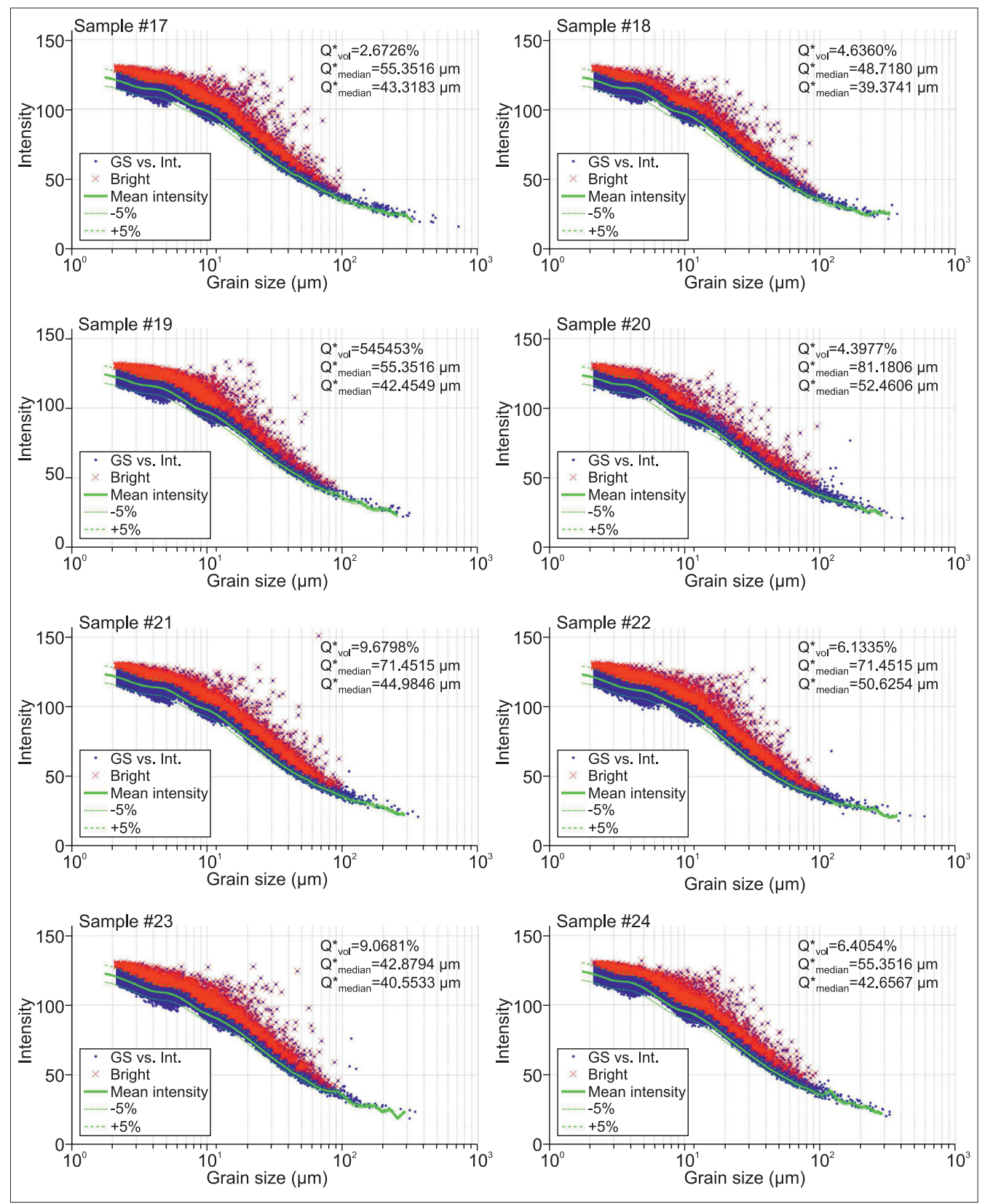

Fig. 6. Continued

while the standard deviation of shape values of carbonates were significantly smaller (Table 2). These phenomena were also recog- nizable on the more platy shape distribution curves of quartz particles compared to the leptokurtic carbonate shape distrubutions. 


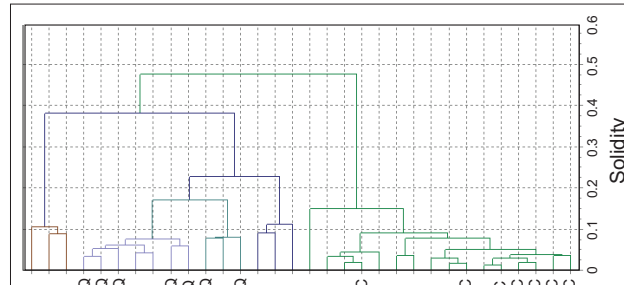

o o o

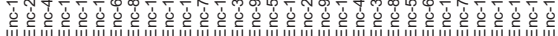

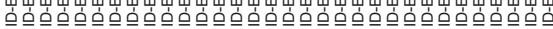

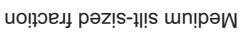

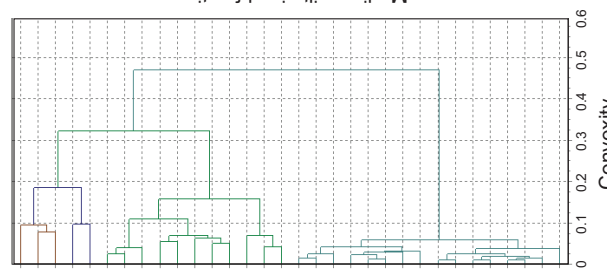

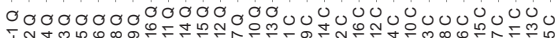
¿ำ

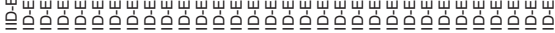

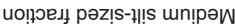

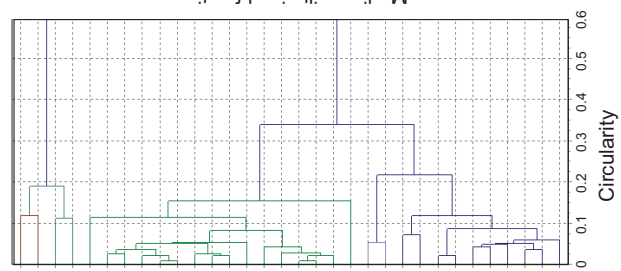

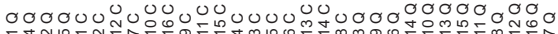

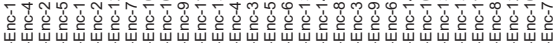

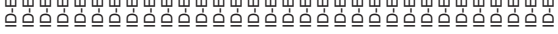

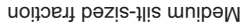

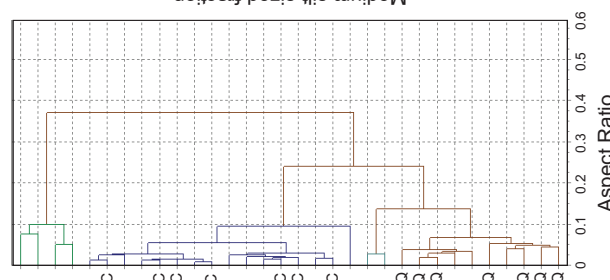

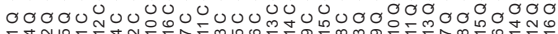

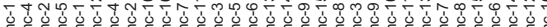

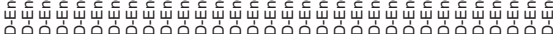
uо!̣วеג! pəz!!s-1!!s un!pəW
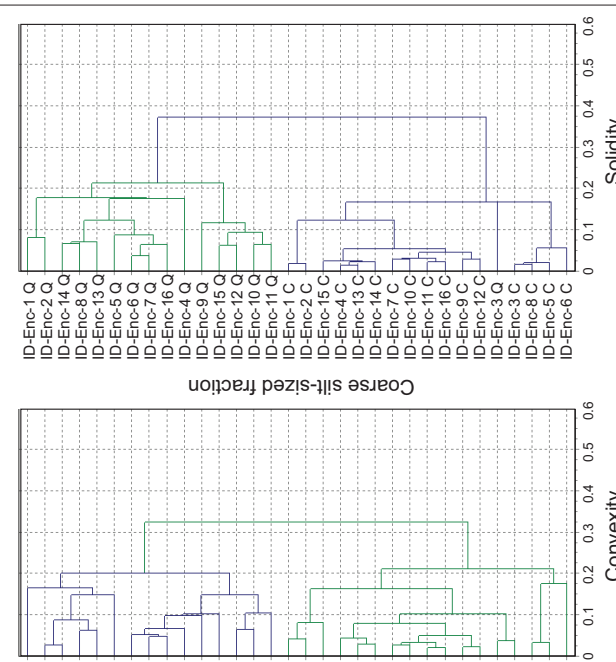

od d O

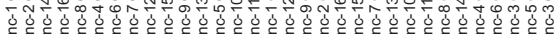

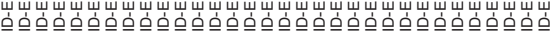

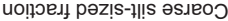

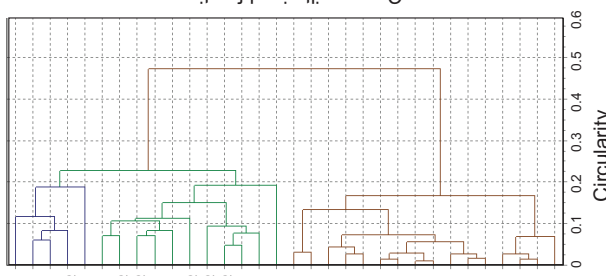

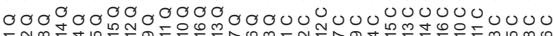

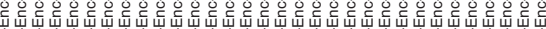

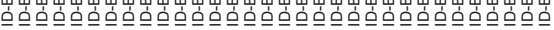

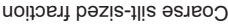

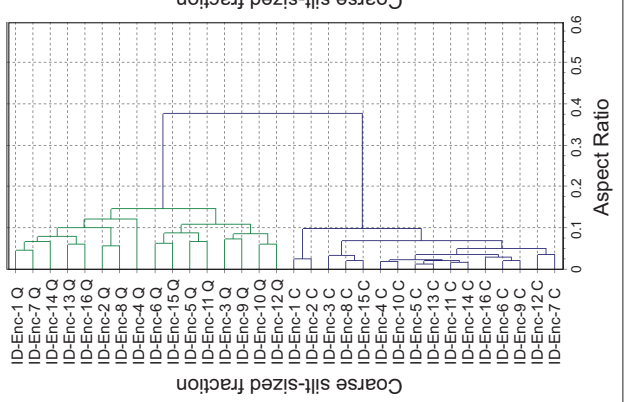




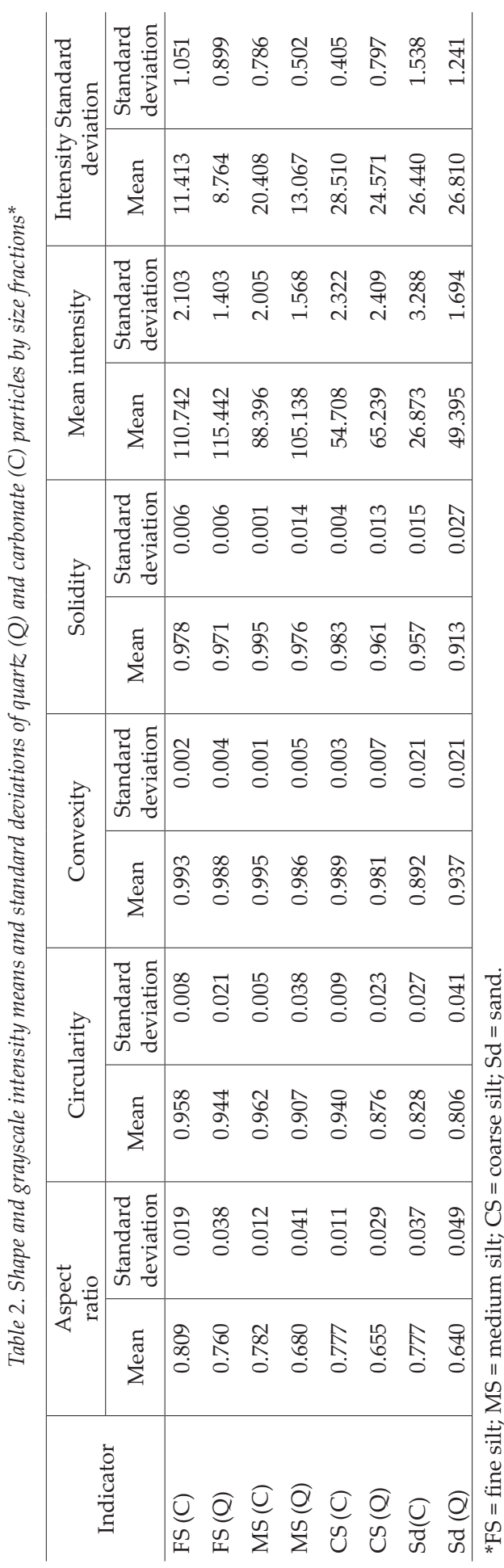

Network analysis showed similar results. More connections among different size fractions of different particle groups marked similar shape properties in Figure 8. It is clearly visible that majority of carbonates were clustered into distinct groups, except for fine silt-sized particles as a result of analogous shapes of smallest particles caused by the relatively low-resolution of the acquired images in this scale.

Medium silt-sized quartz particles showed some clustering in case of more than a half of the samples, but overwhelming majority of coarse sized fractions of quartzes appeared as individual samples without any connection to other ones. As the largest volumetric proportion of supposed Saharan dust material is falling into the coarse silt-sized fraction and even this size population showed the least clustered shape-determined structure, it could be ascertained, that we were not able to find any simple shape parameters to distinguish Saharan dust-related sedimentary populations. However, the joint characterization of size, shape and grayscale intensity properties allowed us to differentiate the North African dust material from local carbonates.

Potential source areas of identified dust particles

The lack of specific shape properties of deposited Saharan dust particles in Fuerteventura can be traced back to diverse geological and pedological character of dust source areas. Previous satellite based studies (e.g. ProsPERO, J.M. et al. 2002; WASHington, R. et al. 2003; Engelstaedter, S. et al. 2006; Goudie, A.S. and Middleton, N.J. 2006; VArga, Gy. 2012) on Saharan dust source areas allowed us to identify potential source areas of mineral dust particles deposited on Fuerteventura. While comprehensive reviews on geochemical characteristics of North African sources provided information on geochemical, mineralogical and isotopic composition of the dust material (Scheuvens, D. et al. 2013).

One of the potential source areas is located in the southern part of the Taoudenni Basin 


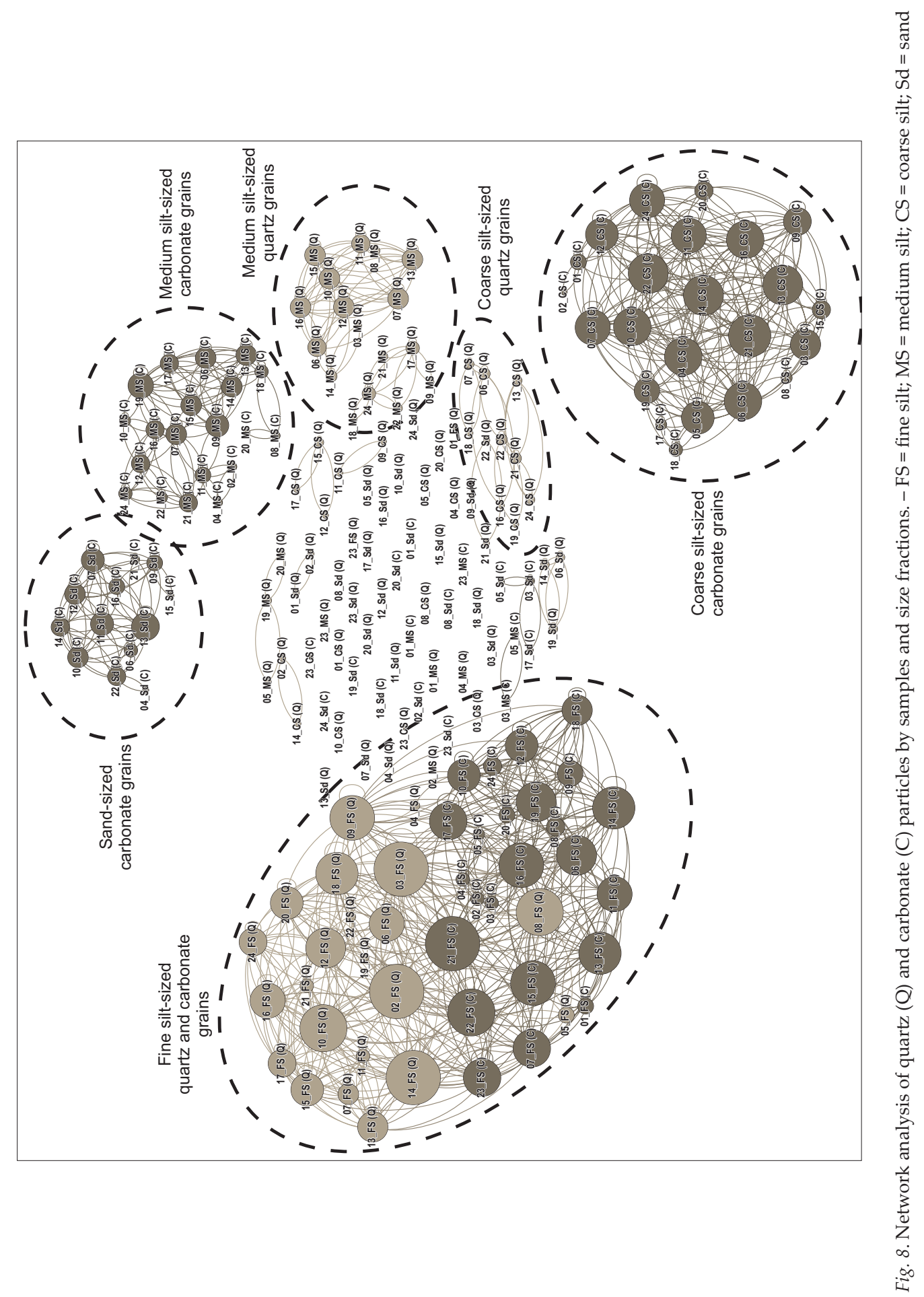


NW from the large bend of Niger River and west from the Adrar des Ifoghas. This area is covered by the deposits of Pleistocene Lake Araouane, one of the largest pluvial lakes in Africa (BRidges, E.M. 1990). The salt and diatomite deposits of the enclosed basin are visible also on satellite images. The prevailing NE trade winds formed an extensive system of barchanoid dunes, partly covering the surface of the ancient lakebed. The dust emission mechanism of the region and intensive deflation of fine-grained particles of lacustrine deposits are enhanced by the bombardment energy of saltating sand particles.

A long narrow band of dust sources is located at the western part of the Sahara at the eastern slopes of gently rolling hills running parallel to the Atlantic coast. Couple of seasonal streams (with frequent flash floods in the spring) and sebkhas (e.g. Sebkha Ijil) lying on the pedimented surface of the Adrar Souttouf and Zemmour Massif are the main sources of fine-grained material in this region.

Several other sources are associated with the large alluvial fans and extensive wadisystem located at the western and northwestern slopes of the Ahaggar. The Tidikelt Depression at northern part of the region, surrounded by plateaus (the Tanezrouft to the south and Plateau du Tademait to the north), by mountains (Ahaggar and Tassili-n-Ajjer to the east) and by the sand sea of Erg Chech to the west has an extensive ephemeral drainage system including several wadis from elevated regions, seasonal marshes and mud flats (Glaccum, R.A. and Prospero, J.M. 1980).

\section{Conclusions}

Automated static image analysis provided huge amount of granulometric (size and shape) data on sedimentary deposits of Fuerteventura. The presented set of methods provided new data on the granulometric character, depositional mechanisms and admixture of dust material to sandy units. Parametric curve-fitting suggested the presence of more than one key depositional mechanisms,
Raman-spectroscopy of manually targeted individual particles revealed a general relationship among grain size, grayscale intensity and mineralogy, while intensity based assessment technique was introduced for identification of large number of quartz particles. All three presented evaluation methods have their own advantages and drawbacks. Parametric curve fitting is a relatively fast technique, it is only based on single one grain size distribution, but it does not take any shape or mineralogy-related information into consideration. Raman spectroscopy provide direct chemical identity data on the selected particles, but generally the number of characterized grains is several orders of magnitude smaller than the whole investigated particle population. The grayscale intensity-based assessment is an indirect technique, but it is suitable for identification of large number of exotic particles.

According to our results, there is no specific granulometric fingerprint parameter for identification of Saharan dust material in the deposits of Fuerteventura, but joint applications of several size, shape and grayscale intensity values and mathematical techniques allowed the separation of quartz particles from other local sedimentary units.

However, the lack of robust granulometric characterization of largest fractions, caused by the wide polydispersity of the mineral deposits, did not allow a stable quantitative assessment of volumetric amount of quartz material. Determination of the total mass of deposited Saharan dust material is a more difficult question in the area, as in most of dust and sediment samples from North African source areas, quartz was found to be the most dominant mineral, but the carbonate-content of dust is also relevant, what can be also interesting in case of Fuerteventura. The calcite content and consequently the $(\mathrm{Ca}+\mathrm{Mg}) /$ Fe ratio of western sources are among the highest in North Africa. The reason for high carbonate content of other mentioned sources is unclear at the moment, but it can be stated that almost all discussed emission regions had relatively high carbonate content. 
Acknowledgement: Support of the National Research, Development and Innovation Office NKFIH K120620 is gratefully acknowledged.

\section{REFERENCES}

Barkan, J., Alpert, P., Kutiel, H. and Kishcha, P. 2005. Synoptics of dust transportation days from Africa toward Italy and Central Europe. Journal of Geophysical Research. Atmospheres 110. D07208.

Bridges, E.M. 1990. World Geomorphology. Cambridge, Cambridge University Press.

Centeri, Cs., Szalai, Z., Jakab, G., Barta, K., Farsang, A., Szabó, Sz. and Bíró, Zs. 2015. Soil erodibility calculations based on different particle size distribution measurements. Hungarian Geographical Bulletin 64. (1): 17-23.

Coude-Gaussen, G., Rognon, P., Bergametti, G., Gomes, L., Strauss, B., Gros, J.M. and Le Coustumer, M.N. 1987. Saharan dust on Fuerteventura Island (Canaries): Chemical and mineralogical characteristics, air mass trajectories, and probable sources. Journal of Geophysical Research 92. D8.

Criado, C. and Dorta, P. 2003. An unusual, 'blood rain' over the Canary Islands (Spain). The storm of January 1999. Journal of Arid Environments 55. 765-783.

Criado, C., Torres, J.M., Hansen, A., Lillo, P. and NARANJo, A. 2012. Intercalaciones de polvo sahariano en paleodunas bioclásticas de Fuerteventura (Islas Canarias). Cuaternario y Geomorfología 26. (1-2): 73-88.

Engelstaedter, S., Tegen, I. and Washington, R. 2006. North African dust emissions and transport. EarthScience Reviews 79. (1-2): 73-100.

Faust, D., Yurena, Y., Willkommen, T., Roettig, C., Richter, Dan., Richter, Dav., von Suchodoletz, H. and ZöLLER, L. 2015. A contribution to the understanding of late Pleistocene dune sand-paleosol-sequences in Fuerteventura (Canary Islands). Geomorphology 246. 290-304.

Ginoux, P.M., Chin, I., Tegen, I., Prospero, J., Holben, M., Duвoviк, O. and Lin, S.J. 2001. Global simulation of dust in the troposhere: model description and assessment. Journal of Geophysical Research 106. 20255-20273.

Glaccum, R.A. and Prospero, J.M. 1980. Saharan aerosols over the tropical North Atlantic: mineralogy. Marine Geology 37. 295-321.

Goudie, A.S. and Middleton, N.J. 2006. Desert Dust in the Global System. Springer.

Harrison, S.P., Kohfeld, K.E., Roelandt, C. and Claquin, T. 2001. The role of dust in climate changes today, at the last glacial maximum and in the future. Earth-Science Reviews 54. 43-80.

Israelevich, P.L., Levin, Z., Jospeh, J.H. and Ganor, E. 2002. Desert aerosol transport in the Mediterranean region inferred from the TOMS aerosol index. Journal of Geophysical Research. Atmospheres 107: D21.
Jackson, M.L., Levelt, T.W.M., Syers, J. K., ReX, R.W., Clayton, R.N., Sherman, G.D. and Uehara, G. 1971. Geomorphological relationships of troposphericallyderived quartz in the soils of the Hawaiian Islands. Soil Science Society of America, Proceedings 35. 515-525.

Jacomy, M., Venturini, T., Heymann, S. and Bastian, M. 2014. ForceAtlas2, a Continuous Graph Layout Algorithm for Handy Network Visualization Designed for the Gephi Software. PLoS ONE 9. (6): e98679.

Kohfeld, K.E. and Tegen, I. 2007. Record of Mineral Aerosols and Their Role in the Earth System. Treatise on Geochemistry 4. 1-26.

Lim, J., Matsumoto, E. and Kitagawa, H. 2005. Eolian quartz flux variations in Cheju Island, Korea, during the last 6,500 $\mathrm{yr}$ and a possible Sun-monsoon linkage. Quaternary Research 64. 12-20.

MACLEOD, D.A. 1980. The origin of the red Mediterranean soils in Epirus, Greece. Journal of Soil Science 31. 125-136.

Maher, B.A., Prospero, J.M., Mackie, D., Gaiero, D., Hesse, P.P. and Balkanski, Y. 2010. Global connections between eolian dust, climate and ocean biogeochemistry at the present day and at the last glacial maximum. Earth-Science Reviews 99. 61-97.

Mahowald, N.M., Kohfeld, K., Hansson, M., Balkanski, Y., Harrison, S.P., Prentice, I.C., Schulz, M. and RodHe, H. 1999. Dust sources and deposition during the last glacial maximum and current climate: a comparison of model results with paleodata from ice cores and marine sediments. Journal of Geophysical Research 104. 15895-15916.

Mahowald, N.M., Muhs, D.R., Levis, S., Rasch, P.J., Yoshioka, M., Zender, C.S. and Luo, C. 2006. Change in atmospheric mineral aerosols in response to climate: Last glacial period, preindustrial, modern, and doubled carbon dioxide climates. Journal of Geophysical Research 111. D10202.

Mee, A.C., Bestland, E.A. and Spooner, N.A. 2004. Age and origin of Terra Rossa soils in the Coonawarra area of South Australia. Geomorphology 58. 1-25.

Menéndez, I., Díaz-Hernández, J.L., Mangas, J., Alonso, I. and SÁnchez-Soto, P.J. 2007. Airborne dust accumulation and soil development in the North-East sector of Gran Canaria (Canary Islands, Spain). Journal of Arid Environments 71. 57-81.

Menéndez, I., Pérez-Chacón, E., Mangas, J., Tauler, E., Engelbrecht, J.P., Derbyshire, E, Cana, L. and Alonso, I. 2013. Dust deposits on La Graciosa Island (Canary Islands, Spain): Texture, mineralogy and a case study of recent dust plume transport. Catena 117. 133-144.

Miller, R.L., Tegen I. and Perlwitz, J. 2004. Surface radiative forcing by soil dust aerosols and the hydrologic cycle. Journal of Geophysical Research. Atmospheres 109. D04203.

Muns, D.R., Budahn, J.R., Prospero, J.M. and Carey, S.N. 2007a. Geochemical evidence for African dust 
inputs to soils of western Atlantic islands: Barbados, the Bahamas, and Florida. Journal of Geophysical Research 112. F02009.

Muns, D.R., Budahn, J.R., Reheis, M., Beann, J., Skipp, G. and FisHER, E. 2007b. Airborne dust transport to the eastern Pacific Ocean off southern California: Evidence from San Clemente Island. Journal of Geophysical Research 112. D13203.

Pósfai, M. and Buseck, P.R. 2010. Nature and climate effects of individual tropospheric aerosol particles. Annual Review of Earth and Planetary Sciences 38. 17-43.

Prospero, J.M. 1996. Saharan dust transport over the north Atlantic Ocean and Mediterranean: An overview. In The impact of desert dust across the Mediterranean. Eds.: Guerzoni, S. and Chester, R., Environmental Science and Technology Library 11, Dordrecht and London, Kluwer, 133-152.

Prospero, J.M. and Lamb, P.J. 2003. African droughts and dust transport to the Caribbean: Climate change implications. Science 302. 1024-1027.

Prospero, J.M., Bonatti, E., Schubert, C. and Carlson, T.B. 1970. Dust in the Caribbean atmosphere traced to an African dust storm. Earth and Planetary Science Letters 9. (3): 287-293.

Prospero, J.M., Ginoux, P.M., Torres, O., Nicholson, S.E. and GILL, T.E. 2002. Environmental characterization of global sources of atmospheric soil dust identified with the Nimbus-7 Total Ozone Mapping Spectrometer (TOMS) absorbing aerosol product. Reviews of Geophysics 40. 1-31.

Roettig, C-B., Kolb, T., Wolf, D., Baumgart, P., Richter, C., Schleicher, A., Zöller, L. and Faust, D. 2017. Complexity of aeolian dynamics (Canary Islands). Palaeogeography, Palaeoclimatology, Palaeoecology 472. 146-162.

Roettig, C-B., Varga, G., Sauer, D., Kolb, T., Wolf, D., Makowsky, V., Recio Espejo, J.M., Zöller, L. and FAUST, D. Characteristics, nature and formation of palaeosurfaces within dunes on Fuerteventura. Quaternary Research (in press)

Scheuvens, D., Schütz, L., Kandler, K., Ebert, M. and Weinbruch, S. 2013. Bulk composition of northern African dust and its source sediments - A compilation. Earth-Science Reviews 116. 170-194.

Shao, Y., Wyrwoll, K.H., Chappell, A., Huang, J., Lin, Z., McTainsh, G.H., Mikami, M., Tanaka, T.Y., WANGH, X. and Yoon, S. 2011. Dust cycle: An emerging core theme in Earth system science. Aeolian Research 2. 181-204.

Stuut, J-B.W., Smalley, I. and O'Hara-Dhand, K. 2009. Aeolian dust in Europe: African sources and European deposits. Quaternary International 198. 234-245.

Sun, D., Bloemendal, J., Rea, D.K., An, Z., VAndenberghe, J., Lu, H., Su, R. and Liu, T.S. 2004. Bimodal grain-size distribution of Chinese loess, and its paleoclimatic implications. Catena 55. 325-340.
Sun, D., Bloemendal, J., Rea, D.K., Vandenberghe, J., JiANG, F., AN, Z. and Su, R. 2002. Grain-size distribution function of polymodal sediments in hydraulic and aeolian environments, and numerical partitioning of the sedimentary components. Sedimentary Geology 152. 263-277.

Swap, R., Garstang, M., Greco, S., Talbot, R. and KallberG, P. 1992. Saharan dust in the Amazon basin. Tellus B 44. (2): 133-149.

Tegen, I., Lacis, A.A. and Fung, I. 1996. The influence of mineral aerosols from disturbed soils on climate forcing. Nature 380. 419-422.

Tsoar, H. and Pye, K. 1987. Dust transport and the question of desert loess formation. Sedimentology 34. 134-153.

Varga, Gy, Cserháti, Cs., Kovács, J. and Szalai, Z. 2016. Saharan dust deposition in the Carpathian Basin and its possible effects on interglacial soil formation. Aeolian Research 22. 1-12.

VARGA, GY. 2012. Spatio-temporal distribution of dust storms - a global coverage using NASA Total Ozone Mapping Spectrometer aerosol measurements (1979-2011). Hungarian Geographical Bulletin 61. (4): 275-298.

VArGA, Gy., Kovács, J. and ÚjvárI, G. 2012. Late Pleistocene variations of the background aeolian dust concentration in the Carpathian Basin: an estimate using decomposition of grain-size distribution curves of loess deposits. Netherlands Journal of Geosciences - Geologie en Mijnbouw 91. (1-2): 159-171.

Varga, Gy., Kovács, J., Szalai, Z., Cserháti, Cs. and ÚJVÁRI, G. 2018. Granulometric characterization of paleosols in loess series by automated static image analysis. Sedimentary Geology 370. 1-14.

VARGA, GY., ÚJvÁrI, G. and KovÁcs, J. Interpretation of sedimentary (sub)populations extracted from grain size distributions of Central European loesspaleosol series. Quaternary International (in press)

von Suchodoletz, H., Kühn, P., Намbach, U., Dietze, M., Zöller, L. and Faust, D. 2009. Loesslike and palaeosol sediments from Lanzarote (Canary Islands/Spain). - Indicators of palaeoenvironmental change during the Late Quaternary. Palaeogeography, Palaeoclimatology, Palaeoecology 278. (1-4): 71-87.

Washington, R., Todd, M., Middleton, N.J. and Goudie, A.S. 2003. Dust-storm source areas determined by the Total Ozone Monitoring Spectrometer and surface observations. Annals of the Association of American Geographers 93. (2): 297-313.

YAALON, D.H. 1997: Soils in the Mediterranean region: what makes them different? Catena 28. 157-169.

YAALON, D.H. and Ganor, E. 1973. The influence of dust on soils during the Quaternary. Soil Science 116. 146-155. 
